\title{
Topics and Topicalization in American Sign Language
}

\author{
Debra Aarons \\ Department of General Linguistics, University of Stellenbosch
}

\section{Overview}

This paper presents a syntactic analysis of Topics in American Sign Language (henceforward ASL), in the Principles and Parameters framework (Chomsky 1986 a,b, $1991,1992)^{1}$. Topics in American Sign Language occur in a structural position to the left of the Complementizer Phrase. Researchers have previously identified topics by a particular non-manual marking, thought to accompany all topics. In this paper, a distinction is drawn between base-generated and moved topics, and, moreover, there is shown to be a difference among the non-manual markings accompanying at least three different sorts of topics. In addition, topic position is shown to be structurally present in embedded as well as main clauses. Extraction is argued to be possible from within an embedded clause to the topic position of the main clause, in the case of non-finite embedded clauses. A maximum of two topics can be adjoined to CP in ASL. If the sentence has two topics, only some combinations of the different sorts of topics are allowed. 
2. The Structural Position in which Topics Occur

Items with topic marking appear at the beginning of the sentence in ASL. Below are some examples of sentences that have items bearing topic marking. 2

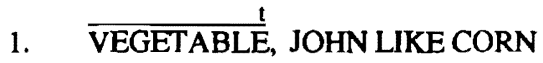

'As for vegetables, John likes com.'

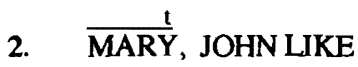

'Mary, John likes.'

3. $\frac{\text { MARY }}{i}_{i}$ JOHN LIKE IX-3rd ${ }_{i}^{3}$

'As for Mary, John likes her.'

4. $\frac{\text { t }}{\text { JOHN, LIKE MARY }}$

'John likes Mary.'

5. $\frac{\mathrm{t}}{\mathrm{JOHN}_{i}}, \mathrm{IX}-3 \mathrm{rd}_{i}$ LIKEMARY

'As for John, he likes Mary.' 
It has been suggested by Lillo-Martin (1990) that the position in which topics occur in ASL is the Spec of CP. However, this cannot be correct if, as argued in Aarons 1994; Aarons, Bahan, Kegl, and Neidle 1992; Neidle, Kegl, Bahan, Aarons and MacLaughlin (in press) the Spec of CP position - the position to which whwords move - is to the right of the IP, since items bearing topic marking occur sentence-initially. Items bearing topic marking occupy a position to the left of CP, which will be called the Topic Position. Furthermore, as can be seen in 6, topics can co-occur with a wh-word that has moved rightward to the Spec of $\mathrm{CP}$.

6. $\frac{t}{\text { JOHN }}, \quad \bar{B} \bar{U} \bar{Y} \bar{Y} \bar{E} \overline{S T E} \bar{E} \bar{D} \bar{A} \bar{Y}-\frac{w h}{\text { WHAT }}$

'John, what did he buy yesterday?'

In such constructions, the non-manual wh-marking cannot extend over the NP in topic position.

7. * JOHN, BUY YESTERDAY WHAT

The spread of wh-marking in 6 and 7 suggests that items appearing in topic position are not c-commanded by the head Complementizer, and therefore are not within $\mathrm{CP}$, as argued in Aarons 1994. This is because the wh-marking that optionally extends over the c-command domain of the +wh Comp cannot extend over the word in topic position (despite the fact that the non-manual wh-marking and topic marking are not incompatible, as shown by Aarons 1994). The topic position, therefore, is postulated to be left-adjoined to the CP. 
Proposed structure

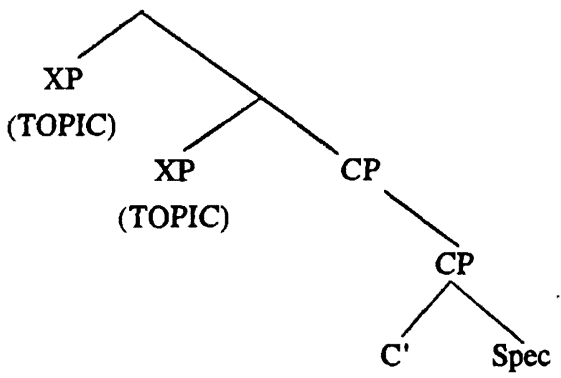

Figure 1 Proposed Structure for Topics in ASL

\section{Non-manual Marking}

Non-manual topic marking typically consists of raised eyebrows and chin (Coulter, 1979; Liddell, 1978, 1980; Baker-Shenk, 1983). Frequently the head is lowered concurrently with the latter part of the sign. The non-manual topic marking always accompanies some manual item, and begins slightly before the onset of the signing. There is usually a slight pause between the signing of the topic-marked item and the rest of the sentence, sometimes accompanied by an eyeblink. There are also other ways of signalling topics non-manually. One of these is body-shifting from side to side. The signer shifts and uses the space to the one side of his body to sign the topic part of the utterance, then shifts to the other side to sign the rest of the utterance. The break between the two parts of the utterance is visibly discemible. Non-manual topic marking may also involve widening of the eyes, and may be followed by a few rapid headnods.

Traditionally, descriptions of topic marking have made no distinction among the different kinds of topics that may occur. There are, in fact, different non-manual 
markings appearing over items in topic position and these are correlated with different kinds of topics.

Non-manual topic marking may co-occur with other non-manual markings. When wh-words appear in topic position, they retain their inherent wh-marking (slightly lowered brows), and can, additionally, be topic-marked, usually by raised chin and a slight tensing of the muscles of the upper cheekbones, ${ }^{4}$ as in Sentence 8 . This is shown in Figure 2.

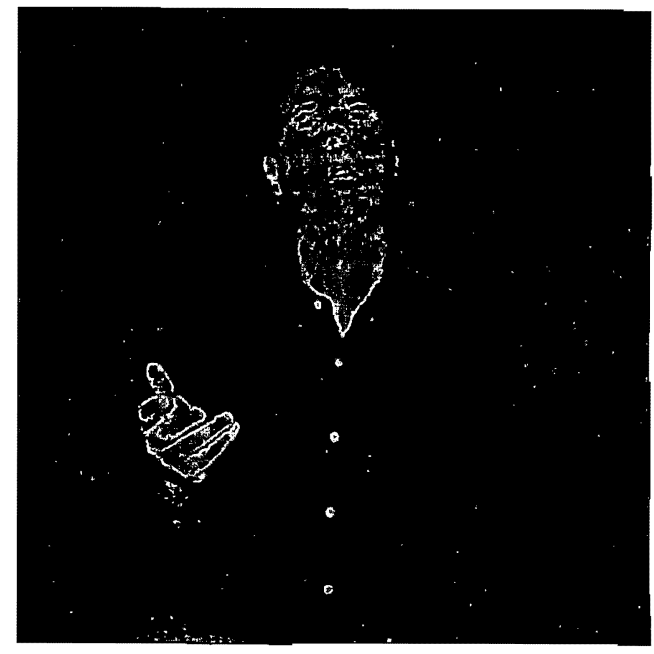

Figure 2 Wh-word in topic position wh/t

\section{WHAT JOHN $\overline{\mathrm{BU}} \overline{\mathrm{WHAT}}$}

'What, what did John buy?'

It is occasionally possible to find items in topic position without the typical nonmanual marking described above, but such topics are usually established in a specific spatial location by indexation or represented in the location by a classifier, and set off from the rest of the sentence by a pause, as in 9.5 


\section{JOHN G-CL, MARY cl\#HIT \\ 'John (there) Mary (him) hit.'}

All constituents in topic position do, however, exhibit some form of topic marking, be it facial expression, shifting to the side, or establishment in a specific spatial location by indexation or the use of a classifier.

In a sentence consisting of a single clause, topic marking occurs only over constituents occurring to the left of CP. ${ }^{6}$ Moreover, topic marking does not spread over any other elements in the sentence, as shown by the ungrammaticality of $10-12$.

\section{0. * $\frac{\mathrm{t}}{\mathrm{JOHN}}-\overline{\mathrm{M}} \overline{\mathrm{A}} \overline{\mathrm{R}} \overline{\mathrm{Y}} \overline{\mathrm{L}} \overline{\mathrm{O}} \overline{\mathrm{V}} \overline{\mathrm{E}}$ \\ 11. * $\overline{\mathrm{JOHN}} \bar{i}, \overline{\mathrm{MARY}} \overline{\mathrm{LOVE}} \overline{\mathrm{I}} \overline{\mathrm{X}}-\overline{\mathrm{rd}} \overline{\mathrm{d}}_{i}$ \\ 12. * $\frac{\mathrm{t}}{\text { VEGETABLE}, ~} \overline{\mathrm{J} O \overline{\mathrm{H}} \mathrm{N}} \overline{\mathrm{L} I K} \overline{\mathrm{E}} \overline{\mathrm{C}} \overline{\mathrm{O}} \overline{\mathrm{R}} \overline{\mathrm{N}}$}

Despite the fact that the topic position is hypothesized to be left-adjoined to $\mathrm{CP}$, and therefore to $\mathrm{c}$-command the $\mathrm{CP}$, the non-manual topic marking may not extend beyond the constituents in topic position. As argued in Aarons 1994, the Topic Phrase does not head a functional projection.

\section{The Relation of Topic Phrases to Other Items in the Sentence}

There are two different ways in which constituents in topic position may be related to the CP to which they are adjoined. Some are base-generated in topic position, while others have moved to topic position from within the $C P$.

\subsection{Base-generated Topics}

Constituents may be base-generated in topic position. Clearly the topic in 13 must be base-generated in that position, since it does not constitute an argument of the main verb (although, as is not unusual in this kind of construction, the topic does bear a 
semantic relation to an argument of the main clause-that of class: element of the class). ${ }^{7}$

13. $\frac{\mathrm{t}}{\mathrm{VEGETABLE}}$, JOHN LIKE CORN

'As for vegetables, John likes com.'

Sentence 14 also has a base-generated topic (although in this case, note that the topic is coreferential with one of the arguments in the sentence, namely the IX in object position).

14. $\frac{\mathrm{t}}{\text { MARY }}_{i}$, JOHN LIKE IX-3rd

'As for Mary, John likes her.'

In both 13 and 14 , the NP in topic position is not an argument of the main verb, and cannot have moved to topic position from an argument position within the CP.

\subsection{Topics That Have Moved}

It is, however, possible for constituents to move from their d-structure position to the topic position left-adjoined to CP. In this section, plain verbs will be used for sample sentences in order to eliminate the possibility of alternative analyses of the sentences under discussion. ${ }^{8}$ These verbs require a lexically overt object as can be seen in 15 and 16.

\section{JOHN LOVE MARY}

'John loves Mary.'

16. * JOHN LOVE

'John loves.' 
Sentence 16 is ungrammatical because it is missing the argument required by the verb. Notice, however, that 17 is grammatical:

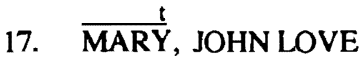 \\ 'Mary John loves.'}

Sentence 17 is hypothesized to be grammatical because of a trace in object position, as illustrated in 18.

18. $\frac{t}{\text { MARY }}_{i}$, JOHN LOVE $t_{i}$

'Mary John loves.'

It is clear, therefore, that there are sentences in which the object argument moves to topic position. 9

\subsection{Adjuncts in Topic Position}

It is also possible for an adjunct, such as TOMORROW, to appear in topic position. 10

19. $\frac{t}{\text { TOMORROW, JOHN PLANE ARRIVE TIME } 6}$

'Tomorrow, John's plane arrives at 6.'

In ASL, locatives are usually signed first in an utterance. These occur in topic position, and are generally topic-marked, as shown in 20 .

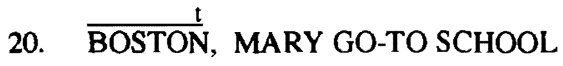

'In Boston, Mary goes to school.' 


\subsection{Semantic Differences Correlated with Non-manual Markings for} Base-generated and Moved Topics

In the gloss system employed in the ASL literature, there is no distinction made among the subtly different non-manual expressions used to mark the various functions of items that occupy topic position. A close examination reveals that there are at least three distinct topic markings that occur over items in topic position, and that each of these is associated with a particular function. Moreover, each topic marking is correlated with a distinct grammatical structure. For ease of exposition, 1 have labelled the three distinct non-manual markings that I have identified as: $\mathrm{tm} 1$, $\operatorname{tm} 2$ and $t \mathrm{~m} 3$. Their non-manual realizations will be discussed in the following sections. Tm1 is used strictly with moved topics, while $\operatorname{tm} 2$ and $\operatorname{tm} 3$ are associated only with base-generated topics. The distinction between $\operatorname{tm} 2$ and $\operatorname{tm} 3$ will be discussed later. Table 1 summarizes the different non-manual markings that accompany different kinds of topics, the grammatical relationship between the topic and the clause, and the semantic relationship between the topic and one of the arguments of the clause. 
Table 1 Topics and Their Relation to CP

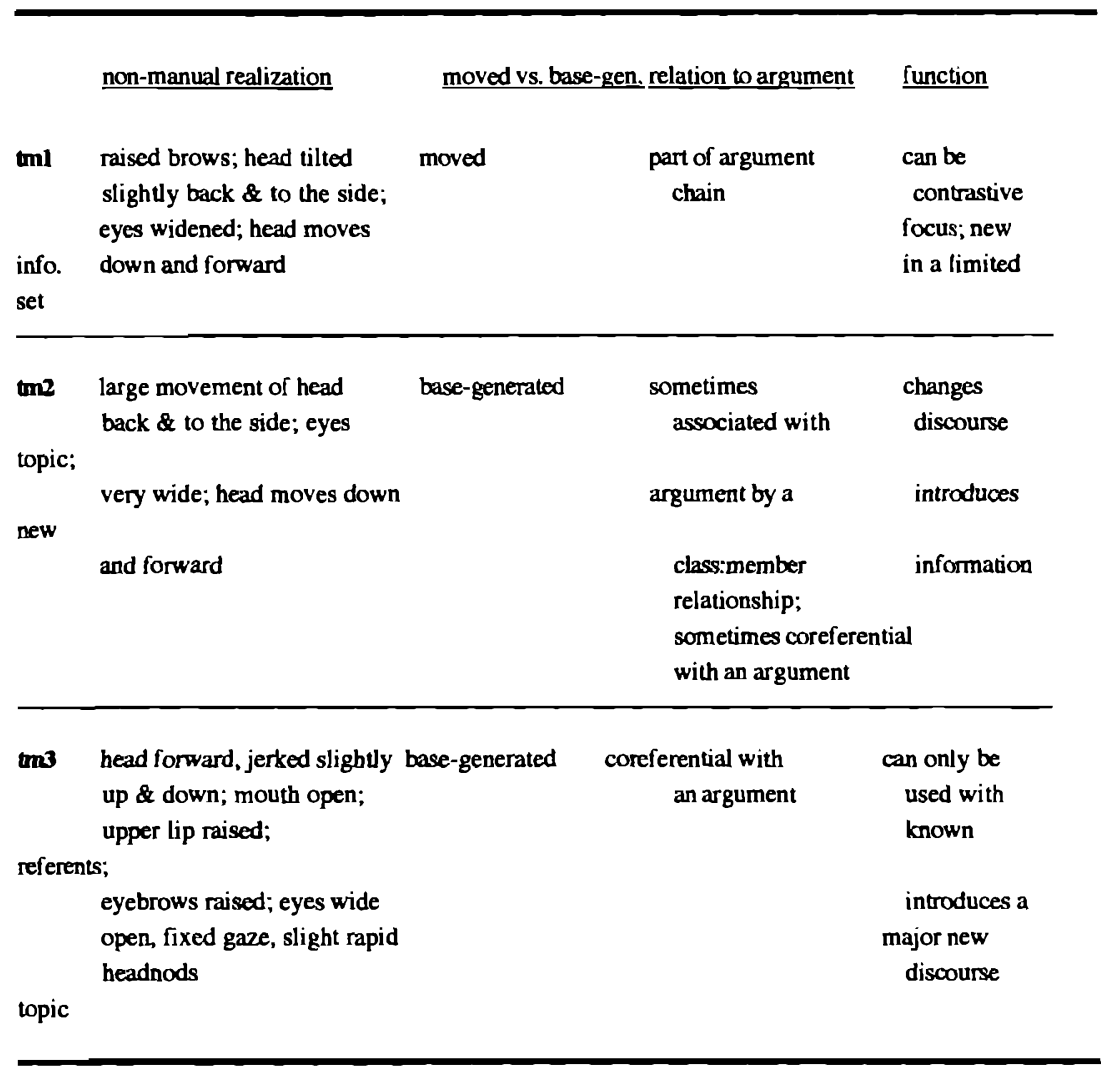

\subsubsection{Moved Topics}

Topic Marking 1. In the case of the structure shown in 21 below, in which an NP has moved to topic position, the non-manual marking over the item in topic position consists of raised brows, head tilted back, sometimes slightly to the side as well, and eyes opened wide. At the final point of the signing of the item in topic position, the head moves down in a nod. There is a pause (and sometimes a brief closing and opening of the eyes ${ }^{11}$ ) before the head returns to neutral position and the next 
constituent is signed. This non-manual marking will be labelled $\mathrm{tm} 1$ (Topic Marking 1) and is shown in Figure 3.

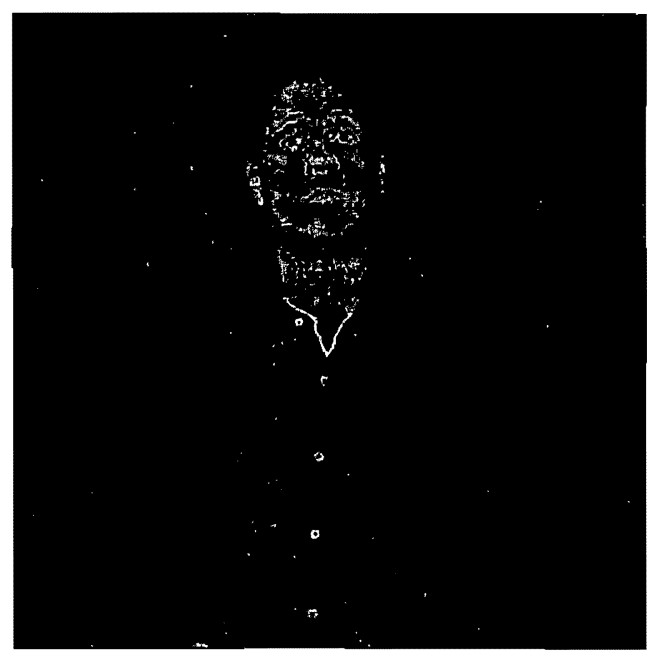

Figure 3 Topic Marking 1

21. $\frac{\mathrm{ml}}{\operatorname{MARY}}{ }_{i}$, JOHN LOVE $t_{i}$

'Mary, John loves.'

In the case of moved topics, such as shown in 21 , only $\mathrm{tm} 1$ is acceptable. With either $\operatorname{tm} 2$ or $\mathrm{tm} 3$, sentences containing moved topics are ungrammatical as shown in 22 and 23.12

im2

22. * MARY $_{i}$, JOHN LOVE $t_{i}$

'As for Mary, John loves.' 
$\begin{aligned} \text { 23. * } & \frac{\operatorname{tm} 3}{\operatorname{MARY}}{ }_{i} \text {, JOHN LOVE } t_{i} \\ & \text { 'You know Mary, John loves.' }\end{aligned}$

Furthermore, tm 1 cannot occur with an item in topic position, if the topic is basegenerated there, rather than moved, as shown in 24 .

24. * $\frac{\mathrm{tm}^{\mathrm{m} 1}}{\mathrm{MARY}_{i}}$, JOHN LOVE IX-3rd
'Mary, John loves her.'

A sentence like 21, with tm1, occurs most naturally in the following different contexts:

1) In a rather limited universe of discourse (in which there is a closed set, which is known) the topic is one member of the set (Kuno, 1987). Thus, the set might be all the women living in a particular house, and the topic of the sentence would be limited to being a member of that set. Thus it is Mary, from among Mary, Sue, Jane and Ann, whom John loves. This is shown in 25.

25. FOUR WOMEN LIVE IN HOUSE IX. $\frac{t m 1}{\operatorname{MARY}} i$, JOHN LOVE $t_{i}$

'Four women live in that house over there. Mary, John loves.'

2) There is emphasis or contrastive focus on the topic. An ASL context in which it may naturally occur is shown in 26 , where the speaker needs to make clear that it is Mary, rather than Jane, that John loves.

26. JOHN NOT-LIKE JANE. MARY, IX-3rd LOVE.

'John doesn't like Jane. Mary, he loves.'

Thus, the particular non-manual marking described above $(\operatorname{tm} 1)$, has the function of highlighting the topic with respect to other known items in its class (as in 25) or of 
contrasting the item in topic position with some previous item in the discourse (as in 26).

Since in ASL pro subjects are always allowed, a sentence like 27 is potentially ambiguous between a reading on which JOHN is base-generated in topic position with pro in subject position, and one in which the subject NP has moved to topic position.

\section{7. $\frac{t}{\mathrm{JOHN}}$, e LOVE MARY}

Given the correlation between specific non-manual markings and moved vs. basegenerated topics, we can confirm this ambiguity. Both tm1 and tm2 are possiblealthough, as predicted, the two sentences, shown in 28 , would be used under somewhat different circumstances.

28a. $\frac{t m 1}{\mathrm{JOHN}_{i}}, t_{i}$ LOVEMARY

'John loves Mary.'

28b. $\frac{\mathrm{tm} 2}{\mathrm{JOHN}_{i}}$, pro LOVEMARY

'As for John, he loves Mary.'

Sentence $28 \mathrm{~b}$ is more likely to be used in the context where JOHN is being introduced as the new topic of the discourse, and is about to be characterized in terms of some particular information, whereas $28 \mathrm{a}$ is more appropriate where JOHN in topic position is either used as one of a limited set of people who could love Mary, or else used contrastively with some others who might not love Mary. 


\subsubsection{Base-generated Topics}

In the case of base-generated topics, there are at least two different non-manual markings ( $\operatorname{tm} 2$ and $\operatorname{tm} 3$ ) that can accompany the constituent in topic position. The different non-manual markings are associated with different functions and meanings of the items in topic position.

Topic Marking 2. Consider 29, with a base-generated topic.

$\operatorname{tm} 2$

\section{VEGETABLE, JOHN LIKE CORN}

'As for vegetables, John likes corn.'

The non-manual marking accompanying VEGETABLE in 29 consists of a large movement of the head backwards and to the side, raised eyebrows and eyes wide open. Towards the final part of the signing of VEGETABLE, the head moves down and forward to a point very distinctly to the opposite side. There is often a slight eyeblink, and a pause before the head returns to neutral position for the signing of the next constituent. This non-manual marking will be labelled $\operatorname{tm} 2$ and is shown in Figure 4.

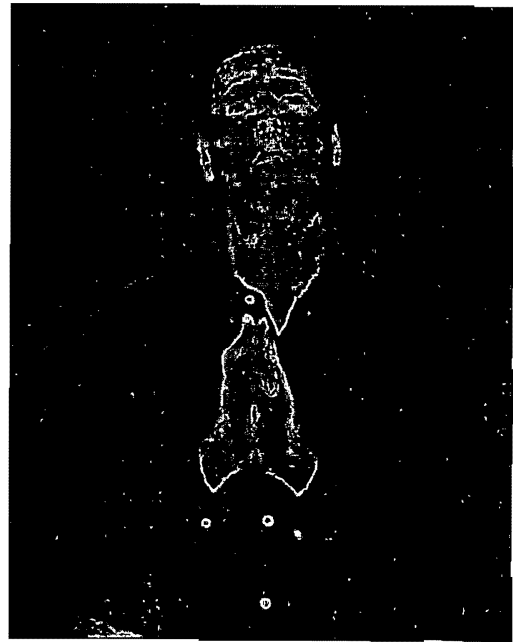

Beginning of Marking

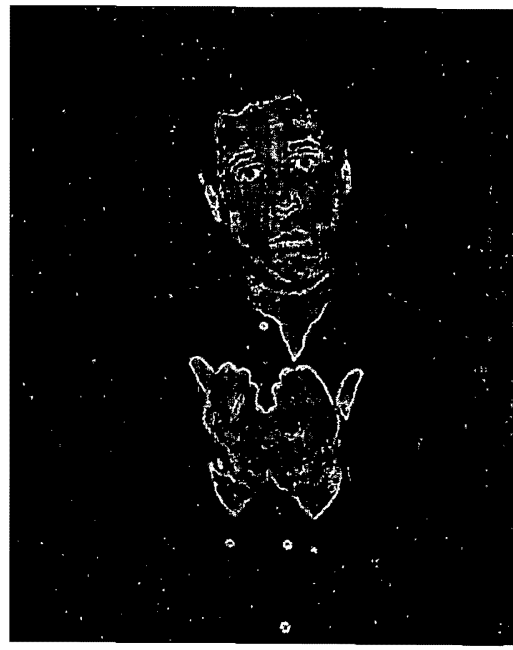

End of Marking 
Sentence 30 shows another base-generated topic (in this case, one that is coreferential with the object argument of the verb). ${ }^{13}$ The non-manual marking ( $\left.\operatorname{tm} 2\right)$ on the item in topic position is identical with that in 29.

\section{m2 \\ 30. FRESH VEGETABLE ${ }_{i}$, JOHN LIKE IX-3rd \\ 'As for fresh vegetables, John likes them.'}

Only base-generated topics may bear the non-manual marking ( $t \mathrm{~m} 2$ ) described here. ${ }^{14}$ Base-generated topics bearing tm 2 may similarly be coreferent with the subject of the sentence, as shown in 31 .

31. $\frac{\mathrm{m} 2}{\mathrm{JOHN}}, \mathrm{IX}-3 \mathrm{rd}_{i}$ LOVEMARY

'As for John, he loves Mary.'

As expected (since pro can occur in subject position in ASL), 32 is also grammatical in a similar context. It bears the identical non-manual marking ( $\mathrm{tm} 2)$ to that of 31 and is judged by informants to have the same meaning as 31.15

32. $\frac{\mathrm{m} 2}{\mathrm{JOHN}}$, e LOVEMARY

'As for John, he loves Mary.'

The function of $\mathrm{tm} 2$ is to introduce new information in a general universe of discourse. This information changes the topic of the discourse. The item in topic position must already be known in some way to the audience, but introducing it as a new topic signals that the speaker is now about to provide a robust characterization of that item. 16

Topic Marking 3. Some base-generated topics may be accompanied by a different 
sort of non-manual marking. The head is down at a slightly forward angle, and jerked up and down, the mouth is open with the upper lip somewhat raised, the eyebrows are raised, as in other topic marking, but the eyes are opened very wide and maintain a fixed gaze, and there is a series of very slight rapid headnods, followed by a pause in which the expression is held, before the signing of the rest of the sentence. This nonmanual marking will be labelled Topic Marking $3(\operatorname{tm} 3)^{17}$ and is shown in Figure 5.

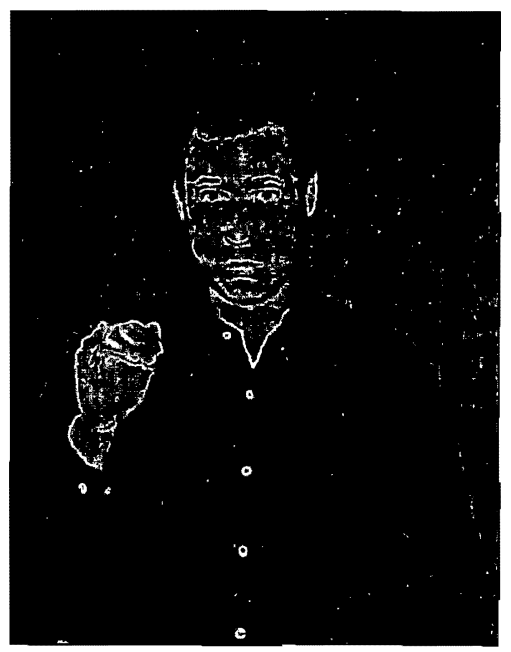

Beginning of Marking

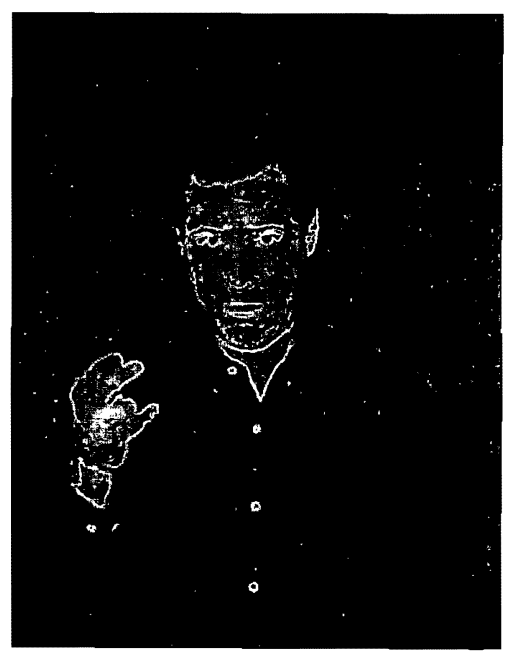

End of Marking

Figure 5 Topic Marking 3

Sentence 33 shows a base-generated topic coreferential with the object argument.

33. $\frac{\mathrm{tm} 3}{\mathrm{MARY}_{i}}$, JOHN LOVE IX-3rd $_{i}$

'(You know) Mary, John loves her.' 
Sentence 34, with the same non-manual marking (tm3) over the topic as in 33, is disfavored, and 33 is strongly preferred, again showing that $\operatorname{tm} 3$ does not mark moved topics.

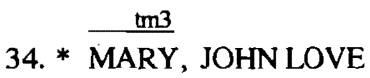

With this same non-manual marking $(\mathrm{tm} 3)$, base-generated topics may also be coreferential with the subject of the verb. This is shown in 35 .

\author{
tm 3 \\ 35. $\mathrm{JOHN}_{i}$, IX-3rd ${ }_{i}$ LOVE MARY \\ '(You know) John, he loves Mary.'
}

However, while 34 is ungrammatical, 36 with pro in subject position is acceptable, and nearly identical in meaning to 35 .

36. $\frac{\mathrm{m} 3}{\mathrm{JOHN}}$, pro LOVE MARY
'(You know) John, he loves Mary.'

When (tm3) appears over the item in topic position, it has the function of introducing as a new discourse topic information that the speaker believes is al ready shared or known by the addressee. Kuno (p.c.) maintains that for this kind of topic in various languages, including English, there is a minimum requirement that the item in topic position be specific enough that the audience can visualize or assume something about it. ${ }^{18}$ This expresses what Coulter (1979), talking about ASL, refers to as a "definite description" of one of the arguments. 
Thus, it can be seen that there are at least three different non-manual markings that accompany topics in ASL. The distinct non-manual markings provide important evidence about the structure of the sentences containing those topics. Topics that are moved may only bear one kind of non-manual marking, $t \mathrm{ml}$, and this non-manual marking may not be bome by base-generated topics. Topics that are base-generated may bear different kinds of non-manual markings, $\operatorname{tm} 2$ or $\operatorname{tm} 3$, depending on their function in the discourse, but neither of these non-manual markings may be borne by moved topics. Examination of these different non-manual markings in sentences with plain verbs, i.e., those that require overt lexical objects, allows us to differentiate moved topics (tm 1$)$ and base-generated topics ( $\mathrm{tm} 2$ and $\operatorname{tm} 3)$ associated with an argument in object position. The distribution of these markers in sentences containing topics associated with subjects of the sentence are consistent with those observed for objects.

\section{Topic Position of Embedded Clauses}

In the case of sentences containing embedded clauses, there is a topic position immediately to the left of the embedded clause in which topic-marked constituents may occur. Sentence 37 shows a sentence with a finite embedded clause containing a plain verb.

\section{TEACHER REQUIRE JOHN MUST LIPREAD MOTHER}

'The teacher requires that John must lipread Mother.'

In sentence 38 , the subject of the embedded clause has moved to the embedded topic position. In sentence 39 , the object of the embedded clause has moved to the embedded topic position. 
38. TEACHER REQUIRE $\frac{\text { tml }}{\mathrm{JOHN}}$, MUST LIPREAD MOTHER

'The teacher requires that John must lipread Mother'

(in the context where it is John, not Bill, that must lipread Mother).

39. TEACHER REQUIRE $\frac{\text { tml }}{\text { MOTHER, JOHN MUST LIPREAD }}$

'The teacher requires that Mother, John must lipread.'

(in the context where John must lipread his mother, not his father).

It is thus possible, under a contrastive focus reading, for either the subject or object argument of the embedded clause to move to the embedded topic position. It is also possible for topics to be base-generated in the embedded topic position. Example 40 shows a sentence with an embedded clause, and 41 illustrates a case where a basegenerated topic within the embedded clause is coreferential with the argument in object position. 19

40. TEACHER EXPECT JOHN WILL LIPREAD MOTHER

'The teacher expects that John will lipread Mother.'

\section{tm2 \\ 41. TEACHER EXPECT MOTHER $_{i}$, JOHN WILL LIPREAD IX-3rd \\ 'The teacher expects that, as for Mother, John will lipread her.'}

Thus, constituents occurring in the topic position of the embedded clause may have been moved there or base-generated there.

\section{Restrictions on Movement}

It has been shown that in a simple clause, both subjects and objects may be 
moved to a position left-adjoined to CP. It has also been shown in Section 5 above that arguments may move to the topic position of the embedded clause. As is demonstrated in the sentences below, arguments of an embedded clause may also move to the topic position of the main clause, but only if the embedded clause is nonfinite. Sentence 42 shows a sentence with an embedded clause; 43 shows the sentence with the embedded subject moved to the topic position of the main clause; and 44 shows the embedded object moved to the topic position of the main clause.

\section{TEACHER REQUIRE JOHN LIPREAD MOTHER}

'The teacher requires John to lipread Mother.'

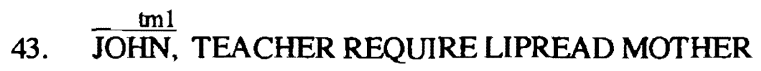

'John, the teacher requires to lipread Mother.'

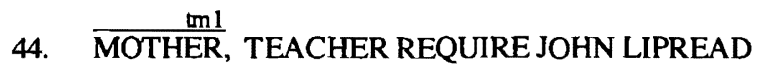

'Mother, the teacher requires John to lipread.'

Sentences 43 and 44 show that it is indeed possible for the subjects and objects of embedded clauses to move to the topic position of the main clause. However, this is not always the case. Consider 45,46 , and 47.20

45. TEACHER REQUIRE JOHN MUST LIPREAD MOTHER

'The teacher requires that John must lipread Mother.'

46. * $\frac{\text { tm } 1}{\text { JOHN }}$, TEACHER REQUIRE MUST LIPREAD MOTHER

47. * $\frac{t m l}{\text { MOTHER, TEACHER REQUIRE JOHN MUST LIPREAD }}$

The contrast in grammaticality of 43 and 46 , and 44 and 47 , correlates with the difference in finiteness of the embedded clause. In 45 , the embedded clause is clearly finite, since a modal occupies the Tense node heading the lower clause, while 42 is 
ambiguous between

a reading on which the embedded clause is tensed or tenseless. 21

So, 47 shows that the object of a finite embedded clause cannot move to the topic position of the higher clause. The structure for 47 is shown in 48 .

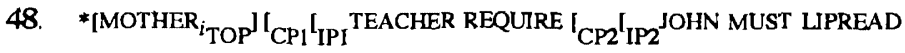
$t_{i} l_{\mathrm{IP} 2} \mathrm{l}_{\mathrm{CP} 2} \mathrm{l}_{\mathrm{IPI}} \mathrm{l}_{\mathrm{CP} 1}$

Movement of the embedded object to the matrix topic position is blocked. Sentence 42 , however, on the reading where the embedded clause is non-finite is shown below.

49. $\left.{ }^{[}{ }_{\mathrm{CP} 1}\left[{ }_{\mathrm{IP} 1} \text { TEACHER REQUIRE }\left[_{\mathrm{IP2}} \text { JOHN LIPREAD MOTHER }\right]_{\mathrm{IP} 2}\right]_{\mathrm{IP1} 1}\right]_{\mathrm{CP} 1}$

Topicalization from subject position of the non-finite embedded clause is allowed, as in 50,22 and from object position as shown in 51 .

50. [JOHN $\left.{ }_{i \text { TOP }}\right]_{\text {CP1 } 1 \text { IP1 }}$ TEACHER REQUIRE [ IP ${ }^{t_{i}}$ LIPREAD MOTHER $\mathrm{J}_{1 \mathrm{P} 2}{ }^{\mathrm{IP}{ }^{\mathrm{I}} \mathrm{CP} 1}$

51. [MOTHER $]_{\text {TOP }}\left[_{\text {CP1 }}\left[_{\text {IP1 }}\right.\right.$ TEACHER REQUIRE $\left[_{\text {IP2 }}\right.$ JOHN LIPREAD $\left.\left.\left.{ }_{i}\right]_{\mathrm{IP} 2}\right]_{1 \mathrm{P} 1}\right]_{\mathrm{CP} 1}$

Confirmation of this claim that arguments may not be extracted from finite embedded clauses comes from sentences with verbs that require tensed complements. The verb SAY in ASL takes only tensed complements. A sentence with an embedded tensed complement is shown in 52 .

\section{TEACHER SAY JOHN LIPREAD MOTHER}

'The teacher said John lipread Mother.' 
Extraction from both subject and object position of the embedded clause to the embedded topic position is possible.

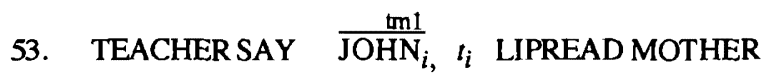

'The teacher said John lipread Mother.'

54. TEACHER SAY $\frac{\text { im } 1}{\operatorname{MOTHER}_{i}}$, JOHN LIPREAD $t_{i}$

'The teacher said Mother John lipread.'

However, extraction from subject and object position of the embedded clause to the matrix topic position is ungrammatical.

55. * $\frac{\mathrm{tm} 1}{\mathrm{JOHN}_{i}}$, TEACHER SAY $t_{i}$ LIPREADMOTHER

"John, the teacher said lipread Mother."

\author{
tm1 \\ 56. * MOTHER $i$, TEACHER SAY JOHN LIPREAD $i$ \\ 'Mother, the teacher said John lipread.'
}

Thus, in ASL, there is a difference in the extraction possibilities of arguments from finite and non-finite embedded clauses. Arguments may not be moved to the topic position of the main clause out of a finite embedded clause.

7. Constituents That Can Appear in Topic Position

Only phrasal constituents may occur in topic position (Liddell 1977, 1980). Thus, a V may not occur in topic position, as shown in 57.

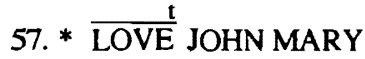


VP's, however, may occur in topic position, as shown in 58.

58. $\frac{\mathrm{tm} 2}{\text { LOVEMARY, }}, \frac{\mathrm{hn}}{\mathrm{JOHN}}$

'As for loving Mary, John does.'

It was first pointed out by Liddell (1977) that when VP's occur in topic position, a headnod obligatorily occurs over the subject in the main clause (containing no lexical realization of VP). Compare 58 with 59.

59. * $\frac{\operatorname{tm} 2}{\text { LOVEMARY, JOHN }}$

'As for loving Mary, John.'

As Liddell showed, this headnod cooccurs with a null $\mathrm{V}$ in a variety of constructions, including gapping and Verb Phrase Deletion. (See Aarons Bahan, Kegl and Neidle, 1992, 1995; andAarons 1994 for further discussion.)

An entire CP may also appear in topic position, as shown in 60 and 61.23

60. JOHN MUST LIPREAD MOTHER, TEACHER NOT REQUIRE

'About John having to lipread Mother, the teacher does not require (it).'

61. JOHN MUST LIPREAD MOTHER, TEACHER REQUIRE

'About John having to lipread Mother, the teacher requires (it).'

The entire propositional argument expressed by a CP in 61 may alternatively be conveyed by THAT. This is shown in 62 . 
62. $\frac{\mathrm{m} 2}{\text { THAT, TEACHER REQUIRE }}$

'... that, the teacher requires.'

Moreover, it has also been claimed by Coulter (1979) that sentences that have the functions of conditionals and when clauses (like 63 and 64) are also CP's occurring in topic position.

63. TOMORROW RAIN, GAME CANCEL

'If it rains tomorrow, the game is cancelled.'

64. IX-3rd GRADUATE, MANY PEOPLECELEBRATE

'When she graduates, many people will celebrate.'

The non-manual marking accompanying these is shown in Figure 6. The non-manual topic markings accompanying when clauses or clauses that express conditional functions are believed to be very similar. The non-manual marking seems to consist of $\operatorname{tm} 2$ with the addition of a feature involving eyegaze that is upward and to the side. 24

8. Maximum of Two Topics

In ASL, there is a maximum of two topics that can be adjoined to CP.

Sentences with three or more topic-marked items are judged to be ungrammatical; the only apparent exception to this is a listing construction. 25 Sentences with more than two topics are rejected by informants. Sentence 65 , with three topics, is ungrammatical. 


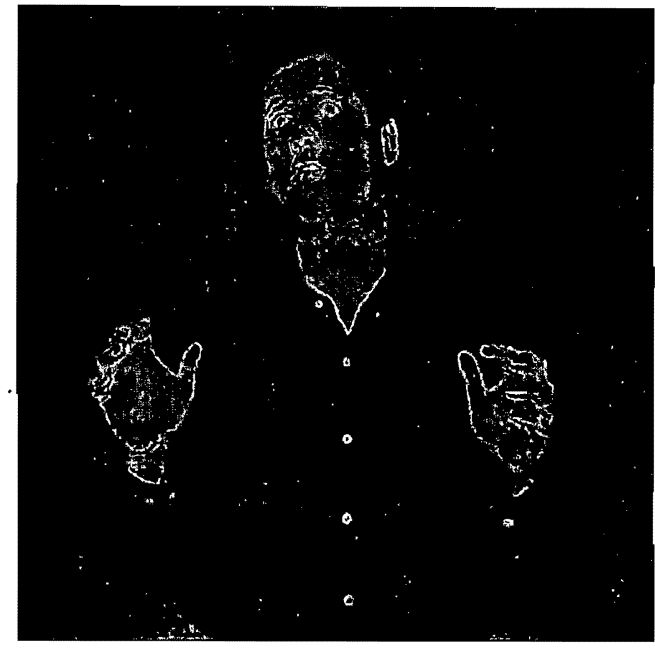

Beginning of Marking

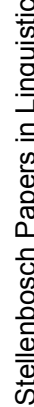

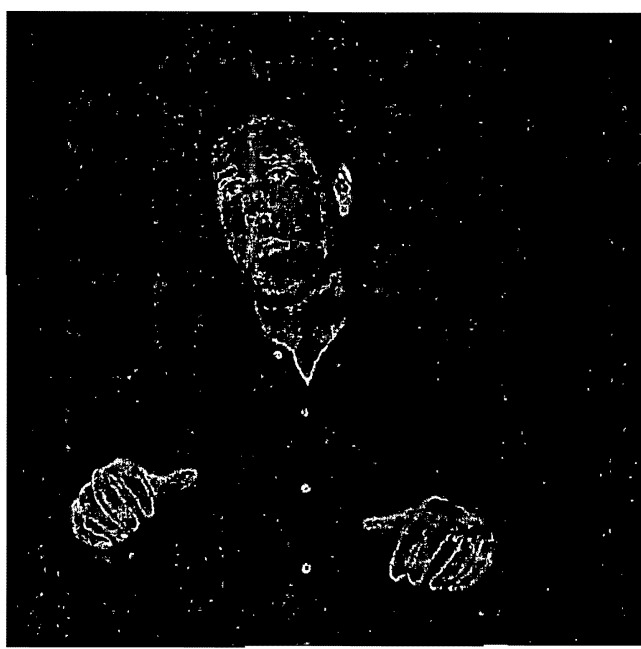

End of Marking

Figure 6 Marking for Conditionals and when clauses 
65. * $\frac{\mathrm{m} 2}{\mathrm{JOHN}_{i}}, \quad \frac{\mathrm{m} 2}{\text { GIRL-group, }} \frac{\mathrm{m} 1}{\text { MARY, IX-3rd }}$ LIKE

'As for John, as for girls, Mary, he likes.'

Sentence 66, however, with two topics, is grammatical.

66. $\frac{\operatorname{tm} 2}{\mathrm{JOHN}_{i}}, \quad \frac{\mathrm{tm} 2}{\text { GIRL-group }}$, IX-3rd ${ }_{i}$ LIKE MARY

'As for John, as for girls, he likes Mary.'

Thus, there are at most two topics in an ASL sentence (Kegl, 1985; Aarons, Bahan, $\mathrm{Kegl}$ and Neidle, 1992). Attempts to introduce three topics at the beginning of a discourse are regularly achieved by distributing the introduction of topics over two or more sentences (Judy Kegl, p.c.).

\subsection{Allowable Combinations of Topics}

Both topics may be base-generated. Sentence 67 has two base-generated topics, neither of which is coreferential with an argument of the verb (but each of which is, instead, in a class: member of class relation).

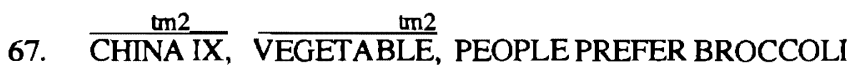

'In China , as far as vegetables are concerned, people prefer broccoli.'

In this case, the ordering of the topics with reference to each other, has no effect on the grammaticality of the sentence. Thus, 68 , although the discourse focus is somewhat different from that of 67 , is also grammatical, with the two topics in the opposite order.

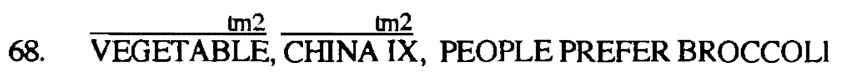

'As for vegetables, in China, people prefer broccoli.' 
Sentence 69 shows two base-generated topics, one of which is coreferential with one of the arguments of the verb. JOHN in topic position is coreferential with IX-3rd in subject position.

69. $\frac{\mathrm{tm} 2}{\mathrm{JOHN}_{i}}, \frac{\mathrm{m} 2}{\mathrm{VEGETABLE}}, \mathrm{IX}-3 \mathrm{rd}_{i}$ PREFER ARTICHOKE

'As for John, as far as vegetables are concerned, he prefers artichokes.'

However, 70, in which the order of topics is reversed, and the topic coreferential with one of the arguments immediately precedes the clause, is found by informants to be ungrammatical.

70. * $\frac{\mathrm{tm} 2}{\text { VEGETABLE, }} \frac{\mathrm{tm} 2}{\mathrm{JOHN}}, \mathrm{IX}-3 \mathrm{rd}_{i}$ PREFER ARTICHOKE

'As far as vegetables are concerned, as for John, he prefers artichokes.'

Sentence 71 shows two base-generated topics, each of which is coreferential with an argument of the verb.

71. $\frac{\mathrm{tm} 2}{\mathrm{JOHN}_{\mathrm{IX}}}, \frac{\mathrm{tm} 2}{\mathrm{MARY} I \mathrm{X}_{j}}, \quad$ IX-3rd LOVE IX-3rd $_{j}$

'John (there), Mary (there), he loves her.'

If the order of the topics is reversed, as in 72 , this makes no difference to the meaning of the sentence. 
72. $\frac{\operatorname{tm} 2}{\text { MARY IX }_{j}}, \frac{\operatorname{tm} 2}{\mathrm{JOHN} \mathrm{IX}_{i}}, 1 \mathrm{X}-3 \mathrm{rd}_{i}$ LOVE IX-3rd $_{j}$

'Mary (located there), John (located there), he loves her.'

If the order of the arguments is reversed, however, so that MARY is the subject and JOHN is the object, as in 73 , the meaning of the sentence changes. The ordering of the two items in topic position does not affect the grammaticality or the meaning of the sentence.

73. $\frac{\operatorname{tm} 2}{\mathrm{JOHN} \mathrm{IX}_{i}}, \frac{\mathrm{tm} 2}{\text { MARY IX }}, \quad$ IX-3rd $\mathrm{rOVEIX}_{j}-3 \mathrm{rd}_{i}$

'John (there), Mary (there), she loves him.'

Thus, the ASL sentence may contain two base-generated topics both marked with tm2. They may occur in either order, except in the case where one of the topics is in a class: member of the class relationship to one of the arguments of the verb. Such a topic must be nearest to the CP.

Informants do not willingly accept 74 , in which one base-generated topic and one moved topic appear in the two topic positions. However, in order for this sentence to be deemed even marginally acceptable, $\operatorname{tm} 2$ must precede $\operatorname{tm} 1$.

74. ? $\frac{\mathrm{tm} 2}{\mathrm{JOHN}_{i}}, \quad \frac{\mathrm{m} 1}{\mathrm{MARY}}, \quad$ IX-3rd LOVE $_{t}$

'As for John, Mary he loves.'

Sentence 75 , which shows the topics in the opposite order, with $\operatorname{tm} 1$ preceding $\operatorname{tm} 2$, is regarded as completely ungrammatical, and much worse than 74 .

75.** $\frac{t \mathrm{~m} 1}{\mathrm{MARY}_{j}}, \quad \mathrm{JOHN}_{i} \operatorname{tX} 2-3 \mathrm{rd}_{i} \operatorname{LOVE}_{t_{j}}$

'Mary, as for John, he loves.' 
If the order of the arguments is reversed, as shown in 76 and 77 , sentence 76 with the moved topic closest to the $\mathrm{CP}$ is marginally acceptable, but 77 is completely ungrammatical.

76. ?? $\frac{\mathrm{tm} 2}{\mathrm{JOHN}_{i}}, \frac{\mathrm{tml}}{\mathrm{MARY}_{j}, t_{j} \text { LOVE IX-3rd }}$

'As for John, Mary loves him.'

77.** $\frac{\mathrm{tml}}{\operatorname{MARY}_{j},}{\frac{\mathrm{m} 2}{\operatorname{JOHN}_{i}}}_{i j} t_{j}$ LOVE IX-3rd $i$

'Mary, as for John, (she) loves him.'

Thus, $\mathrm{tm} 1$ may not precede $\mathrm{tm} 2$. In the marginally acceptable case in which both $\mathrm{tm} 1$ and $\mathrm{tm} 2$ do occur, tm2 must precede $\mathrm{tm} 1$. Some explanations for these restrictions will be provided in 8.2 .

Furthermore, if both topics have $t \mathrm{~m} 1$, i.e., if they are both moved topics, as shown in 78 and 79 , then the sentence is ungrammatical.

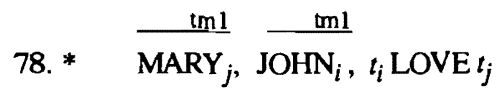

'Mary, John, he loves her.'

79. $* \frac{\mathrm{ml}}{\mathrm{JOHN}_{i}}, \mathrm{MARY}_{j}, t_{i} \operatorname{LOVE}_{j}$

'John, Mary, he loves her.'

Thus, a sentence containing two topics both marked with $\mathrm{tm} l$ is never grammatical, irrespective of the order of the topics.

Sentences 80 and 81 show one base-generated topic with $t \mathrm{~m} 3$, and one moved topic ( $\operatorname{tml}$ ). If $\operatorname{tm} 3$ precedes $t \mathrm{~m} 1$, the sentence is grammatical, as in 80 . However, if the moved topic $(\mathrm{tm} \mathrm{l})$ is first, then the sentence is ungrammatical, as in 81 . 
80. $\frac{\mathrm{tm} 3}{\mathrm{JOHN}_{j}}, \mathrm{MARY_{i }}, \mathrm{IX}-3 \mathrm{rd}_{j}$ LOVE $t_{i}$

'You know John, Mary, he loves.'

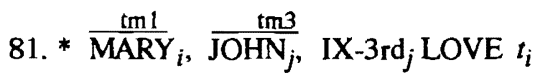

'Mary, you know John, he loves.'

If the arguments are reversed this does not affect the grammaticality of the equivalents of 80 and 81 , shown in 82 and 83 .

82. $\frac{\operatorname{tm} 3}{\operatorname{JOHN}_{j}}, \frac{\operatorname{tm} 1}{\operatorname{MARY}_{i}}, t_{i}$ LOVE IX-3rd

'You know John, Mary, loves him.'

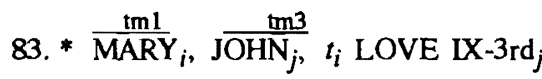

'Mary, you know John, (she) loves him.'

Thus sentences containing two topics, one marked with $\operatorname{tm} 3$ and one with $\operatorname{tm} 1$, are only grammatical when the item marked with $\operatorname{tm} 3$ precedes the item marked with tm1. The order of the arguments of the verb, relative to the order of the topics, is irrelevant.

Sentences with two base-generated topics, one of which is $\operatorname{tm} 3$ and one of which is tm2, are only grammatical when $\operatorname{tm} 3$ precedes $\operatorname{tm} 2$. This is shown in 84 and 85 .

84. $\frac{\operatorname{tm} 3}{\operatorname{JOHN}_{i}}, \frac{\mathrm{tm} 2}{\operatorname{MARY}_{j}}$, IX-3rd LOVE IX-3rd $_{j}$

'You know John, as for Mary, he loves her.' 
85. * $\frac{\operatorname{tm} 2}{\mathrm{MARY}_{i}}, \frac{\mathrm{tm} 3}{\mathrm{JOHN}_{j}}, \mathrm{LX}-3 \mathrm{rd}_{j}$ LOVE IX-3rd $\mathrm{CH}_{i}$

'As for Mary, you know John, he loves her.'

When the order of the arguments is reversed, the grammaticality of the sentences with $\operatorname{tm} 3$ and $\operatorname{tm} 2$ is not affected. The equivalent of 84 is grammatical, whereas the equivalent of 85 is not.

86. $\frac{\operatorname{tm} 3}{\mathrm{JOHN}_{i}}, \frac{\mathrm{tm} 2}{\mathrm{MARY}_{j}}$, IX-3rd LOVE IX-3rd $_{i}$

'You know John, as for Mary, she loves him.'

87. * $\frac{\mathrm{tm} 2}{\mathrm{MARY}_{i}}, \frac{\mathrm{tm} 3}{\mathrm{JOHN}_{j}}, \mathrm{IX}-3 \mathrm{rd}_{i}$ LOVE $\mathrm{LX}-3 \mathrm{rd}_{j}$

'As for Mary, you know John, she loves him.'

Thus, when there are two base-generated topics, one marked with $\operatorname{tm} 3$ and one with $\operatorname{tm} 2$, the sentence is only grammatical when $\operatorname{tm} 3$ precedes $\operatorname{tm} 2$. This ordering is irrespective of the order of the arguments of the verb.

A sentence with two base-generated topics both marked with tm3, as shown in 88, is grammatical. As shown in 89, the order of the arguments does not affect the grammaticality of the sentence.

88. $\frac{\mathrm{tm} 3}{\mathrm{JOHN}_{i}}, \frac{\mathrm{tm} 3}{\mathrm{MARY}_{j}}, \mathrm{IX}-3 \mathrm{rd}_{i}$ LOVE IX-3rd $j$

'You know John, you know Mary, he loves her.'

89. $\frac{\mathrm{tm} 3}{\mathrm{JOHN}_{i}}, \frac{\mathrm{tm} 3}{\mathrm{MARY}_{j}}$, IX-3rd $j$ LOVE IX-3rd $i$

'You know John, you know Mary, she loves him.' 
In sum, ASL sentences may contain a maximum of two topics. Topics marked by $\operatorname{tm} 3$ must precede those marked by $\operatorname{tm} 2$. When there is a moved topic (marked by tm1), it must immediately precede the clause. It may in turn be preceded by $\operatorname{tm} 3$, but not by $\mathrm{tm} 2$. These results are summarized in the table below.

Table 2 Grammaticality of sequences of two topics

\begin{tabular}{|c|c|c|c|c|}
\hline Topic marking & followed by & $\underline{\mathrm{tm} 1}$ & $\underline{\operatorname{tm} 2}$ & $\mathrm{tm} 3$ \\
\hline tml & & * & $*$ & * \\
\hline $\operatorname{tm} 2$ & & $? ?$ & $\sqrt{ }$ & $*$ \\
\hline $\operatorname{tm} 3$ & & $\sqrt{ }$ & $\sqrt{ }$ & $\sqrt{ }$ \\
\hline
\end{tabular}

8.2 Some Explanations for the Allowable Combinations of Topics

As demonstrated above, there seems to be a maximum of two topics that may occur in the ASL sentence. As already discussed, when tml occurs, it occurs either on its own, as in 90 , or following tm3, as in 91 .

90. $\frac{\operatorname{tm} 1}{\mathrm{JOHN}}$, MARY LOVE $t_{i}$

'John, Mary loves.'

91. $\frac{\operatorname{tm} 3}{\operatorname{JOHN}_{j}}, \quad \frac{\operatorname{tml} 1}{\operatorname{MARY}_{i}}, t_{i}$ LOVE IX-3rd

'You know John, Mary loves him.'

It must thus occur in the topic position nearest to the CP. As tml marks only moved topics, it is reasonable to suppose that a moved argument occupies the topic position 
nearest to the $\mathrm{CP}$ in order to properly govern its trace. Movement to the further topic position is not grammatical, as can be seen by the fact that there may not be two moved topics, and the fact that it is never grammatical for a moved topic to occur before any other element in topic position.

Two base-generated topics can occur in the ASL sentence. Base-generated topics marked with tm2, if neither is coreferent with an argument of the verb, may be freely ordered with respect to each other. However, when there are two base-generated topics marked with tm2, as shown in 92 and 93 , and 94 and 95 , when one topic is related to an argument of the sentence by a class: member of the class relationship, then that topic must be nearest to the CP.

92. $\frac{\mathrm{tm} 2}{\mathrm{JOHN}}, \frac{\mathrm{m} 2}{i}, \frac{\text { VEGETABLE, IX-3rd }}{i}$ PREFER ARTICHOKE

'As for John, as far as vegetables are concemed, he prefers artichokes.'

93. * VEGETABLE, $\overline{\mathrm{JOHN}}{ }_{i}, \mathrm{IX}-3 \mathrm{rd}_{i}$ PREFER ARTICHOKE

'As far as vegetables are concerned, as for John, he prefers artichokes.'

When $\mathrm{tm} 2$ marks a class, the proposition that follows it must be a comment about a specific element of the generic class expressed by the topic. Topics marked with tm2 that are coreferent with an argument of the verb can occur in either or both of the topic positions, although in the case where one topic refers to a class, then the topic coreferent with an argument of the verb must precede the class topic.

Two base-generated topics both marked with $\operatorname{tm} 3$ can occur in the ASL sentence. However, when a topic marked with $\mathrm{tm} 3$ cooccurs with a topic marked with either $\operatorname{tm} 1$ or $t \mathrm{~m} 2$, the one bearing $\operatorname{tm} 3$ must occupy the leftmost topic position.

Semantically, items marked with tm 3 function to bring to the forefront of the discourse information that is specific enough for the audience to conceptualize. Once 
this information is established, other topics, such as those introducing new information (marked with tm2), or highlighting something particular (marked with tm1) may be introduced.

\section{Conclusion}

Topics in ASL have been shown to occur in a structural position postulated to be adjoined to the left of CP. Both base-generated and moved topics may occupy topic positions in ASL. Different non-manual markings accompanying different sorts of topics were identified and described. Each non-manual topic marking has been shown to have a unique function, and the item with which each topic marking co-occurs has been found to have a distinct relation to an argument of the verb in the main CP. Topic position is argued to be structurally present in embedded as well as in main clauses. In the case of non-finite embedded clauses, extraction has been shown to be possible to the topic position of the main clause. A maximum of two topics can be adjoined to CP in ASL. If two topics are present in the ASL sentence, only certain combinations of the different sorts of topics are allowable. Other constructions in ASL, previously described as embedded clauses, are claimed here to be CP's in topic position.

\section{Notes}

1. The research reported here is based on a chapter in my dissertation, Aarons, 1994, as weil as on work presented at the 5th International Conference on Sign Language Research, in Montreal, Canada in September 1996. Funding for me to attend the Montreal Conference was provided by a travel grant from the Centre for Science Development of the Human Sciences Research Council of South Africa and the Dean's fund at the University of Stellenbosch. I am grateful to Carol Neidle, Ben Bahan, Judy Kegl, Dawn MacLaughlin, Robert Lee, Donna Lardiere, Dalia Cahana-Amitay, Hoski Thrainsson and Marina McIntire for their valuable comments on various incarnations of this paper.

2. Since English has no real equivalent of these construetions, the glosses used in these examples are at best an approximation of their meaning. A fuller discussion of the different meanings that items in topic position may have is to be found in Section 4.4. In addition, items in topic position are simply marked here with a ' $t$ ', although later a distinction will be made among items with different kinds of topic markings.

3. In the gloss system used here, I use IX to refer to an index point to a particular location in space. Loosely, this can be regarded (in translation) as a pronoun, 1st, 2nd or 3rd person. 
4. This was first pointed out to me by Petronio (p.c.) although her analysis of wh-words sentenceinitially differs entirely from the one presented here.

5. G-CL is the gloss for the upright person classifier, which functions here to establish the NP, John, in a particular location. The same handshape (represented here by cl) is cliticized onto the verb HIT, so that the sign should actualiy be glossed as him-HIT. See Kegl (1986) for a discussion of classifier clitics.

6. Utterances containing parentheticals or role-shifts into direct speech may exhibit topic marking that occurs at the beginning of the parenthetical or the roleshift. Embedded sentences with topics will be discussed in Sections 5 and 6.

7. There is some implicit kind of connection between the topic, VEGETABLE, in 13 and one of the arguments: CORN. CORN is a member of the class that is referred to by the topic.

8. Using verbs that are morphologically plain (i.e., verbs that do not exhibit overt subject and object agreement) eliminates alternative analyses that are based on claims that pro may occur in the object position of an agreeing verb (Lillo-Martin, 1986, 1991). Such proposals have been made to account for the contrast between (i) and (ii). HATE in ASL is of the morphological class of agreeing verbs, whereas LOVE is morphologically plain.
i. $\quad$ BILL $_{i}{ }_{i}$ HATE $_{j} \mathrm{e}_{j}$
'Bill hates (him).'
ii. * JOHNLOVE
'John loves.'

9. The indices marking morphological agreement in (i) have been omitted from glosses generally since, except where noted, morphological agreement is not relevant to the syntactic issues under discussion.

NP's in subject position of a simple sentence may also move to the topic position. Example (i) shows the neutral sentence, meaning 'John loves Mary'; (ii) illustrates a subject NP moved to topic position.

\section{i. JOHN LOVE MARY \\ ii. $\frac{\mathrm{t}}{\mathrm{JOHN}}_{i}, i_{i}$ LOVE MARY \\ 'John loves Mary.'}

Thus, just as object arguments may be topicalized in ASL, subject arguments, too, may be topicalized. As ASL always allows pro in subject position, a case needs to be made that the empty category in subject position may be $t$ rather than pro. Arguments for this are found in 4.4, on the basis of a correlation between moved topics and a particular non-manual marking that accompanies them, as well as on semantic grounds.

10. Both Coulter (1979) and Anderson (1978) observe that there is a tendency for locative and temporal adverbs to appear sentence-initially in ASL, and moreover, observe that they frequently bear topic marking.

11. These sorts of eyeblinks have been identified by Baker and Padden (1978) as occurring optionally at ccrtain constituent boundaries in ASL. Work by Bahan and Supalla (1995) on eye behavior in ASL narratives confirms these findings. 
12. It is true of all the sentences with moved topics in this subsection that they are ungrammatical if marked with $\operatorname{tm} 2$ or $\operatorname{tm} 3$.

13. It should be noted that $\operatorname{tm} 2$ may be used if the topic is related to an argument of the sentence in a class: member of the class relationship (as in 29) or if the topic has a specific referent (as in 30 ). However, if the topic is coreferent with an argument of the verb, it must be definite or specific, not merely generic. Sentence (i) is ungrammatical, because the topic is not definite, whereas (ii), because the topic has been made definite by the addition of IX, is acceptable.

\author{
$\underline{m 2}$ \\ i. * VEGETABLE, IOHN LIKEIX-3rd \\ 'As for vegetables, John likes them.' \\ $\operatorname{tin} 2$ \\ ii. VEGETABLEIX $;$, JOHN LIKE IX-3rd \\ 'As for those vegetables, John likes them.'
}

14. It should be noted that in examples such as (i), used by $\mathrm{Kegl}(1985,1986)$, the item in topic position is marked by tm2. This provides evidence that the clitic is the object argument of the verb, as an NP marked by tm 2 must be base-generated in topic position. This is contrary to the claim made by Lillo-Martin (1991:121) that what Kegl calls object clitics are "formational components of the sign, not separate morphemes." Lillo-Martin's claim would predict that the topic marking in (i) would have to be $\mathrm{tm} 1$ for the sentence to be grammatical, as she would consider JOHN to be a moved argument. The non-manual marking on the topic shows that Lillo-Martin's analysis is incorrect.

$$
\begin{aligned}
& \text { i. } \quad \quad^{\frac{\mathrm{m} 2}{\mathrm{JOHN}_{i}}}, \text { MARY cl\#HTT } \\
& \text { 'As for John, Mary hit him[clitic].' }
\end{aligned}
$$

15. Since it has already been shown that $\mathrm{tm} 2$ is limited to base-generated topics and does not cooccur with moved topics, the empty category in 32 cannot be a trace resulting from movement of the subject argument. The structure proposed for 32 is shown in (i).

i. JOHN, pro LOVEMARY

Since ASL allows pro in the subject position of a sentence containing any type of verb, pro may occur in the subject position of a sentence with a topic marked as tm2.

16. Thus, the item in topic position must be familiar to the audience. If an entirely new concept is being introduced, and the audience is not assumed to know what the lexical item means, this is not an acceptable discourse strategy.

17. This non-manual marking (tm3) has often been described in the literature as the one accompanying restrictive relative clauses (see, inter alia, Liddell, 1978). As Coulter arguesconvincingly, I believe-clauses providing definite description (previously interpreted in the ASL literature as relative clauses) are, in fact, in topic position. Structurally, they are adjoined to the main clause. They serve the function of providing definite information about, or a definite description of, the NP argument with which they are coreferential.

18. Kuno (p.c) also suggests that this sort of topic really functions as a 'hypertopic' and that the audience is about to receive a large amount of information about the item in topic position. It is 
necessary, however, that the audience have some idea of who the person in topic position is. Kuno (1972) argues, as well, that it is quite reasonable to claim that using topics in this way is an altemative form of relativizing an argument, Iending some support to Coulter's (1979) claim that what have, in ASL, been called relative clauses, are, in fact, clauses in topic position.

19. Notice, however, that (i), with $\operatorname{tm} 2$, is ungrammatical, in contrast to 39 which has $t \mathrm{ml}$ over the object in topic position. This is as would be expected, as already seen in the simple sentence in 21. The object MOTHER may not bear $\mathrm{tm} 2$ if it is moved. Moved arguments may only bear $\mathrm{tm} 1$.

i. * TEACHER EXPECT MOTHER, JOHN WILL LIPREAD

'The teacher expects that, as for Mother, John will lipread.'

20. All these sentences are based on the reading in which 'TEACHER REQUIRE' is not a parenthetical.

21. The claim is that the acceptable instances of movement in 43 and 44 involve only the tenseless reading. Note that under that reading, REQUIRE is functioning as an exceptional case marking verb.

22. However, $\mathbf{4 6}$ (shown in (i)) is ungrammatical, showing that the subject of a finite embedded clause cannot be topicalized. This can be explained in terms of the ECP, as shown in (ii). JOHN in topic position, cannot properly govern its trace.

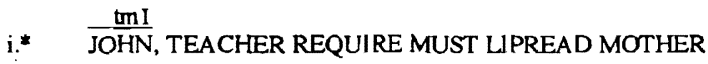

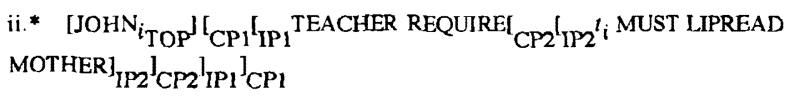

23. Sentence 60 , with negation in the main clause, establishes that the $C P$ is in topic position and rules out the possibility of the parenthetical reading for TEACHER REQURE available for (i) which might otherwise be entertained:

\section{i. JOHN LIPREAD MOTHER, TEACHER REQUIRE}

24. I will not discuss conditional or when clauses in this work. I merely note in passing that the non-manual marking accompanying these clauses appears to be that of topic marking with the addition of a particular eyegaze, and that this feature is borne by items occurring base-generated in topic position.

25. This excludes sentences like (i) below, where there is a list of topics that are embedded inside one main topic:

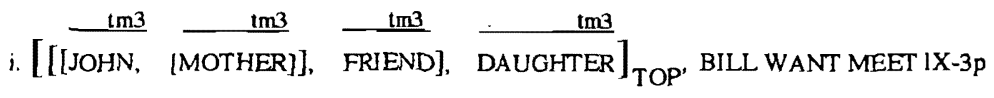

'Know John? Know his mother? Know her friend? Know her friend's daughter? Bill wants to meet her.'

In this case however, note that the unique topic of the sentence is "John's mother's friend's daughter.' 


\section{Bibliography}

Aarons, D. (1994) Aspects of the Syntax of American Sign Language. Doctoral dissertation, Boston University, Boston, MA.

Aarons, D., B. Bahan, J. Kegl, and C. Neidle (1995) Lexical Tense Markers in American Sign Language. In K. Emmorey, and J. Reilly (eds), Sign, Gesture, and Space. Hillsdale, NJ: Lawrence Erlbaum, 225-253.

Aarons, D., B. Bahan, J. Kegl, and C. Neidle (1994) Subjects and Agreement in American Sign Language: In I. Ahlgren, B. Bergman, and M. Brennan (eds), Perspectives on Sign Language Structure: Papers from the Fifth International Conference on Sign Language Research, Volume 1. Durham, England: International Sign Linguistics Association, 13-28.

Aarons, D., B. Bahan, J. Kegl, and C. Neidle (1992) Clausal Structure and a Tier for Grammatical Marking in American Sign Language. Nordic Journal of Linguistics $15: 103-142$.

Anderson, L. (1978). Historical Change and Stability of American Sign Language. Unpublished ms, Gallaudet College, Washington, DC.

Bahan, B. (1996) Non-Manual Realization of Agreement in American Sign Language. Doctoral dissertation, Boston University, Boston, MA.

Bahan, B., J. Kegl, D. MacLaughlin, and C.Neidle (1995) Convergent Evidence for 
the Structure of Determiner Phrases in Amerịcan Sign Language. In L.Gabriele, D. Hardison and R. Westmoreland (eds), FLSM VI, Proceedings of the Sixth Annual Meeting of the Formal Linguistics Society of Mid-America, Volume Two.

Ḅloomington, IN: Indiąna University Linguistics Club Publications, 1-12.

Bahan, B. and S. Supalla, (1995). Line Segmentation and Narrative Structure: A Study of Eye-gaze in American Sign Language. In K. Emmorey, and J. Reilly (eds), Sign, Gesture, and Space. Hillsdale, NJ: Lawrence Erlbaum.

Baker-Shenk, C.L. (1983) A Micro-analysis of the Nonmanual Components of Questions in American Sign Language. Ph.D. dissertation, University of California, Berkeley.

Baker, C. and C. Padden. (1978) Focusing on the Non-manual Components of American Sign Language. In Siple, P. (ed.), Understanding Language Through Sign Language Research. New York: Academic Press. 27-58.

Chomsky, N. 1986-a. Barriers. Cambridge, MA: MIT Press.

Chomsky, N. 1986-b. Knowledge of Language: Its Nature, Origin and Use. New York: Praeger.

Chomsky, N. 1991. Some Notes on the Economy of Derivation and Representation. In Freidin, R. (ed.), Principles and Parameters in Comparative Grammar. Cambridge, MA: MIT Press. 417-454. 
Chomsky, N. 1992. A Minimalist Framework for Linguistic Theory. MIT Occasional Papers in Linguistics. Cambridge, MA.

Coulter, G. (1979) American Sign Language Typology. Unpublished Ph.D. dissertation, University of California, San Diego.

Emmorey, K., and J. Reilly. (eds.) (1995). Sign, Gesture and Space. Hillsdale: Lawrence Erlbaum.

Friedman, L. (1976) The Manifestation of Subject, Opject and Topic in American Sign Language. In Li, C. (ed.), Word Order and Word Order Change. Austin: University of Texas Press. 125-148.

Hoza, J., C. Neidle, D. MacLaughlin, J. Kegl, and B. Bahan (to appear) A Unified Syntactic Account of Rhetorical Questions in American Sign Language. Sign Language Studies.

Kegl, J., C. Neidle, D. MacLaughlin, J. Hoza, and B. Bahan (in press) The Case for Grammar, Order and Position in ASL: A Reply to Bouchard and Dubuisson. Sign Language Studies 90, 1996, 1-23.

Kegl, J. (1985) Locative Relations in American Sign Language Word Formation, Syntax, and Discourse. Unpublished Ph.D. dissertation, Massachusetts Institute of Technology, Cambridge, MA.

Kegl, J. (1986) Clitics in American Sign Language. In Borer, H. (ed.), Syntax and 
Semantics: The Syntax of Pronominal Clitics 19. New York: Academic Press. 285309.

Kegl, J. (1987) Coreference Relations in American Sign Language. In Lust, B. (ed.), Studies in the Acquisition of AnaphoraVol II. Dordrecht: D. Reidel. 135-170.

Kuno, S. (1987) Functional Syntax. Chicago: University of Chicago Press.

Li, C. and S. Thompson. (1976) Subject and Topic. New York: Academic Press.

Liddell, S. (1977) An Investigation into the Syntax of American Sign Language.

Ph.D. dissertation, University of California, San Diego (published as Liddel1, 1980).

Liddell, S. (1978) An Introduction to Relative Clauses in ASL. In Siple, P. (ed.), Understanding Language Through Sign Language Research. New York: Academic Press. 59-90.

Liddell, S. (1980) American Sign Language Syntax. The Hague: Mouton.

Lillo-Martin, D. (1986) Two Kinds of Null Arguments in American Sign Language. Natural Language and Linguistic Theory 4: 415-444.

Lillo-Martin, D. (1990) Parameters for Questions: Evidence from Wh-Movement in ASL. In Lucas, C. (ed.), Sign Language Research: Theoretical Issues.

Washington, DC: Gallaudet University Press. 211-222.

Lillo-Martin, D. (1991) Universal Grammar and American Sign Language. Dor- 
drecht: Kluwer.

McIntire, M. (1980) Locatives in American Sign Language. Unpublished Ph.D. dissertation, University of Califomia, Los Angeles.

Neidle, C., J. Kegl, B. Bahan, D. Aarons, and D. MacLaughlin (in press) Rightward Wh-Movement in American Sign Language. In H. van Riemsdijk, D. LeBlanc and D. Beermann, eds., Rightward Movement. Amsterdam: John Benjamins, in press.

Petronio, K. (1993) Clause Structure in American Sign Language. Unpublished Ph.D dissertation, University of Washington, Seattle. 